\title{
Local measurements of axial and radial strains using magnetic encoders in triaxial apparatus
}

\author{
Marcin Witowski* \\ Building Research Institute, Warsaw, Poland
}

\begin{abstract}
The requirement for implementing local measurements at small strains is well known. Without this type of measurement, it is not possible to accurately identify the soil stiffness characteristics over the entire stiffness degradation curve. The paper presents the results of the use of new sensor based on miniature magnetic encoders for axial and radial deformation measurements in triaxial soil test. Presented results include two types of measurement techniques for radial direction and one for axial deformation.
\end{abstract}

\section{Introduction}

The problem of overestimation of displacements and underestimation of stiffness obtained in laboratory tests, compared to measurements of displacements and stiffness obtained in the field [1], [2], [3], [4], is now widely known in geotechnics. It led to the improvement in the testing procedures at the end of the 1970s. The triaxial apparatus, in its classical form [5], does not allow for accurate estimation of the stiffness of the soil as several effects decrease the reliability of this type of measurement. These include: compliance of load cell, non-parallelism of sample ends, and bedding-in effects [6]. So far, several local strain measurement systems based on linear variable differential transformers (LVDTs), Hall effect sensors, local deformation transducer (LDT), as well as proximity sensors have been built [7]. In addition, strain measurements can also be conducted by scanning the surface of the sample with a specialized optical system analysing the image of the deformed sample. Such measurements are mainly based on the PIV (Particle Image Velocimetry) technique [8] or a scan of the entire volume of the sample with the use of X-rays [9]. However, these methods require specialized and expensive measuring devices and have low resolution and accuracy.

A new type of system of sensors for measuring local displacements based on an encoder has been developed [10]. This system made it possible to measure only axial deformations of soil samples. However, a more detailed examination of soil stiffness also requires the measurement of radial deformations propagating in the sample during shearing [11]. For this purpose, two systems for measuring radial deformations were developed (Fig. 1). The first one is based on the calliper principle proposed by Bishop and Henkel [5] and the second one is based on direct measurements [12], [13]. Due to hardware limitations, currently the maximum number of supported encoder-based sensors can be up to four transducers. Therefore, two sensors were used to measure axial deformations, a calliper radial measurement used one sensor, and the last free sensor was used for direct diameter measurements. This sensor was used only for experimental purposes, in order to check whether the use of one sensor will allow for accurate measurement of radial deformations.

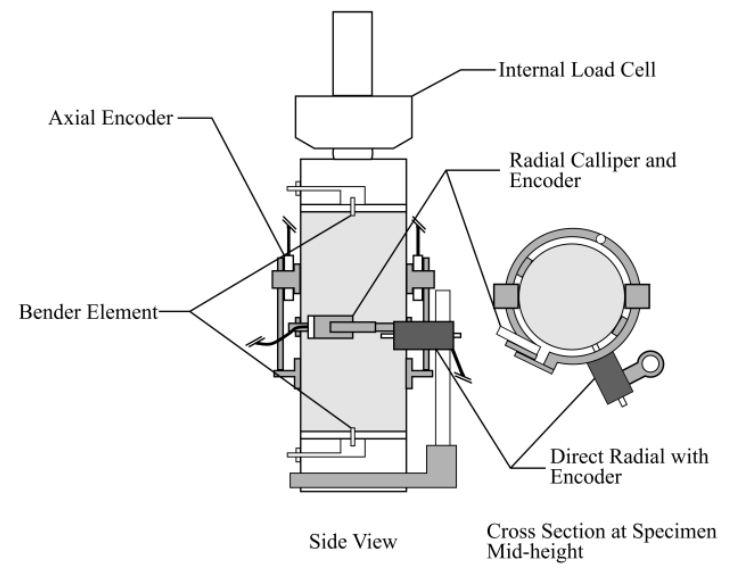

(a)

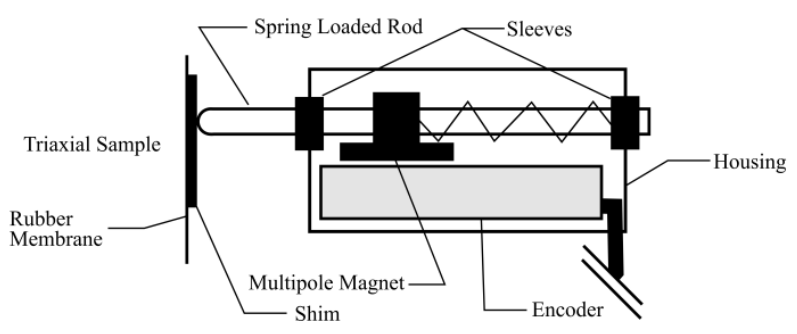

(b)

Fig. 1. Small strain instrumentation: (a), Cross section through direct radial transducer: (b)

\footnotetext{
* Corresponding author: m.witowski@,itb.pl
} 


\section{Experimental program and procedures}

\subsection{Soil}

The test was carried out on a sample of quartz sand from the Biała Góra site, more information about basic parameters of used soil are presented in Table 1 and article [10]. The sample was formed by dry pluviation technique, with relative density $D_{r}$, of $85 \%$. The test was carried out at the value of the confining pressure of $\sigma^{\prime}{ }_{\mathrm{c}}=100 \mathrm{kPa}$, on the sample of $71 \mathrm{~mm}$ diameter and height of $150 \mathrm{~mm}$. Specimen was sheared at a constant rate of strain of $1.0 \%$ per hour.

Table 1. Characteristics of Biała Góra sand.

\begin{tabular}{|c|c|c|}
\hline $\begin{array}{c}\text { Specific } \\
\text { gravity }\end{array}$ & $\mathrm{G}_{\mathrm{s}}$ & 2.65 \\
\hline $\begin{array}{c}\text { Maximum } \\
\text { void ratio }\end{array}$ & $\mathrm{e}_{\max }$ & 0.914 \\
\hline $\begin{array}{c}\text { Minimum } \\
\text { void ratio }\end{array}$ & $\mathrm{e}_{\min }$ & 0.569 \\
\hline $\begin{array}{c}\text { Coefficient } \\
\text { of } \\
\text { uniformity }\end{array}$ & $\mathrm{C}_{\mathrm{u}}$ & 1.91 \\
\hline $\begin{array}{c}\text { Mean grain } \\
\text { size }\end{array}$ & $\mathrm{D}_{50}$ & 0.19 \\
\hline
\end{tabular}

\subsection{Triaxial test}

The test was performed under drained condition to characterize the general stress-strain behaviour of the specimen. The internal deformation measurements made by miniature encoders mounted directly on the specimen were used to calculate axial and radial strains. Proposed small strain measurement system is capable of resolving axial strains as low as $0.001 \%$ and radial strains respectively as low as $0.0003 \%$ (radial calliper) and $0.001 \%$ (direct radial). The axial load was measured using an internal submersible load cell with measurement range of $10 \mathrm{kN}$ and accuracy of $0.003 \mathrm{kN}$. Cell and pore pressure were measured using external pressure transducers. Data from two axial systems, two radial systems, load cell and pressure sensors were recorded every 1 second (Fig. 2).

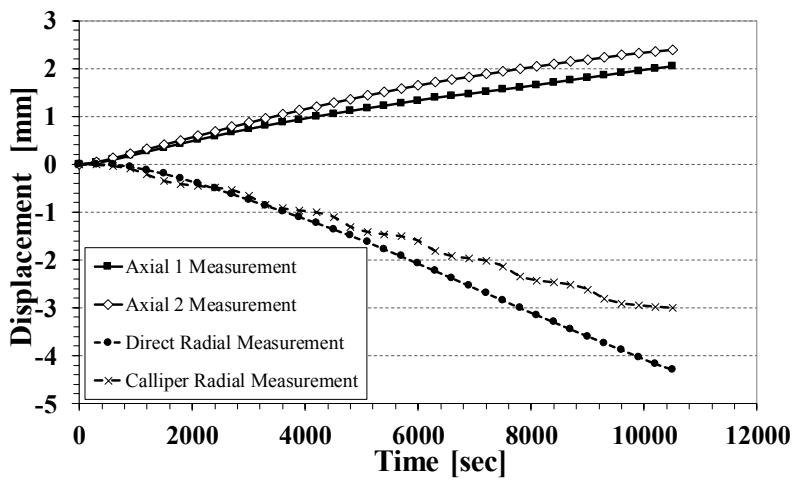

Fig. 2. Measured data from internal transducers
As can be seen, there is a certain inconsistency in the results of both axial and radial sensor displacement measurements. Although, in the case of radial measurements the scatter is larger. In both cases it may result from specimen tilting during shear or from nonconcentric load [14].

Bender element test was conducted after consolidation stage using a single-pulse sinusoidal input signal. In the analysis of the signal, a method of visual interpretation of the signal was applied, where the main signal "peak" transition measurement was focused on the major first peak method [15], [16], [17]. Assuming that the triaxial specimen can be represented as isotropic, infinite and elastic medium, $\mathrm{G}_{\max }$ can be calculated as:

$$
\mathrm{G}_{\max }=\rho V^{2}
$$

where $V$ is the computed velocity and $\rho$ is the bulk density of the specimen when $V$ was measured.

\subsection{Data interpretation}

The assumed symmetrical distribution of forces and stresses allowed to define average normal stresses $p^{\prime}$ and deviatoric stress $q$ as:

$$
\begin{gathered}
p^{\prime}=\left(\sigma_{a}^{\prime}+2 \sigma_{r}^{\prime}\right) / 3 ; \\
q=\sigma_{a}^{\prime}-\sigma_{r}^{\prime}
\end{gathered}
$$

and corresponding shear strain $\varepsilon_{s h}$ is given by:

$$
\varepsilon_{s h}=2\left(\varepsilon_{a}-\varepsilon_{r}\right) / 3
$$

where $\sigma_{a}^{\prime}, \sigma_{r}^{\prime}, \varepsilon_{a}$ and $\varepsilon_{r}$ are axial effective stress, radial effective stress, axial strain and radial strain respectively.

The secant shear modulus has been determined according to the following formula:

$$
G_{s e c}=\Delta q / 3 \Delta \varepsilon_{s h} \text { when } \Delta p=0
$$

\section{Results}

To illustrate the degradation of shear stiffness, the secant shear modulus computed from two types of sensors are plotted versus strain in Fig. 3. Clear differences are seen for shear strains less than $0.03 \%$, with even greater differences at very small strains. This can be due to the friction of the radial sensor rod against the slide bearings or due to the behaviour of the sample itself (tilting of the specimen). Nevertheless, it seems that both sensors allowed to determine the correct initial values of the shear modulus. This conclusion results from the fact that the shear modulus obtained from piezoelectric elements $G_{\max }$, plotted on the graph, shows correspondence with the values of the initial secant shear modulus $G_{\text {sec. }}$. The correspondence between the values of the $G_{\max }$ and $G_{\mathrm{sec}}$ modulus was assumed based on results obtained by other researchers [18], [19], [20], [21]. The following diagram (Fig. 4) shows a normalized secant shear modulus to the maximum shear modulus.

\footnotetext{
Corresponding author: $\underline{\text { m.witowski@itb.pl }}$
} 


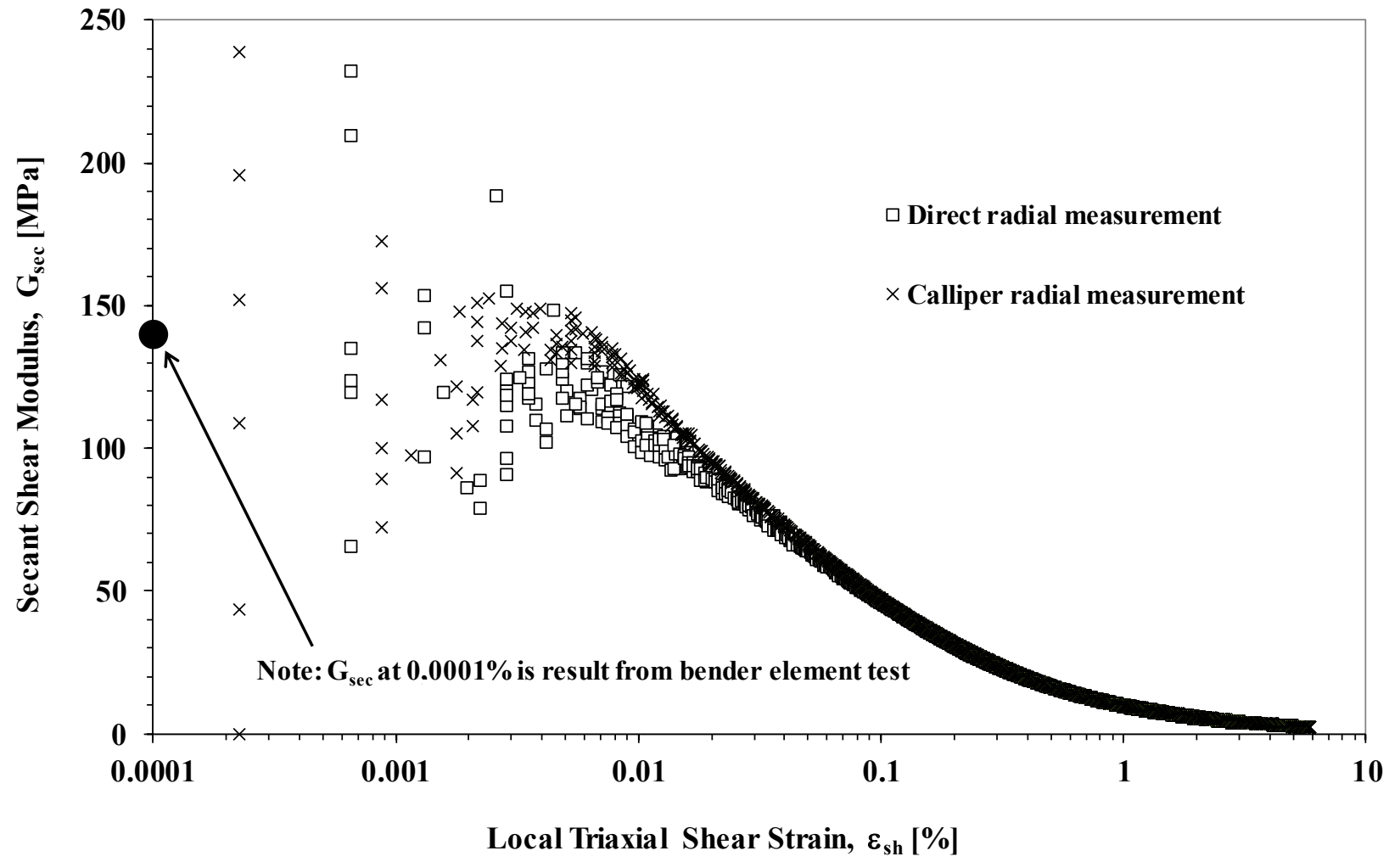

Fig. 3. Secant shear modulus degradation curve

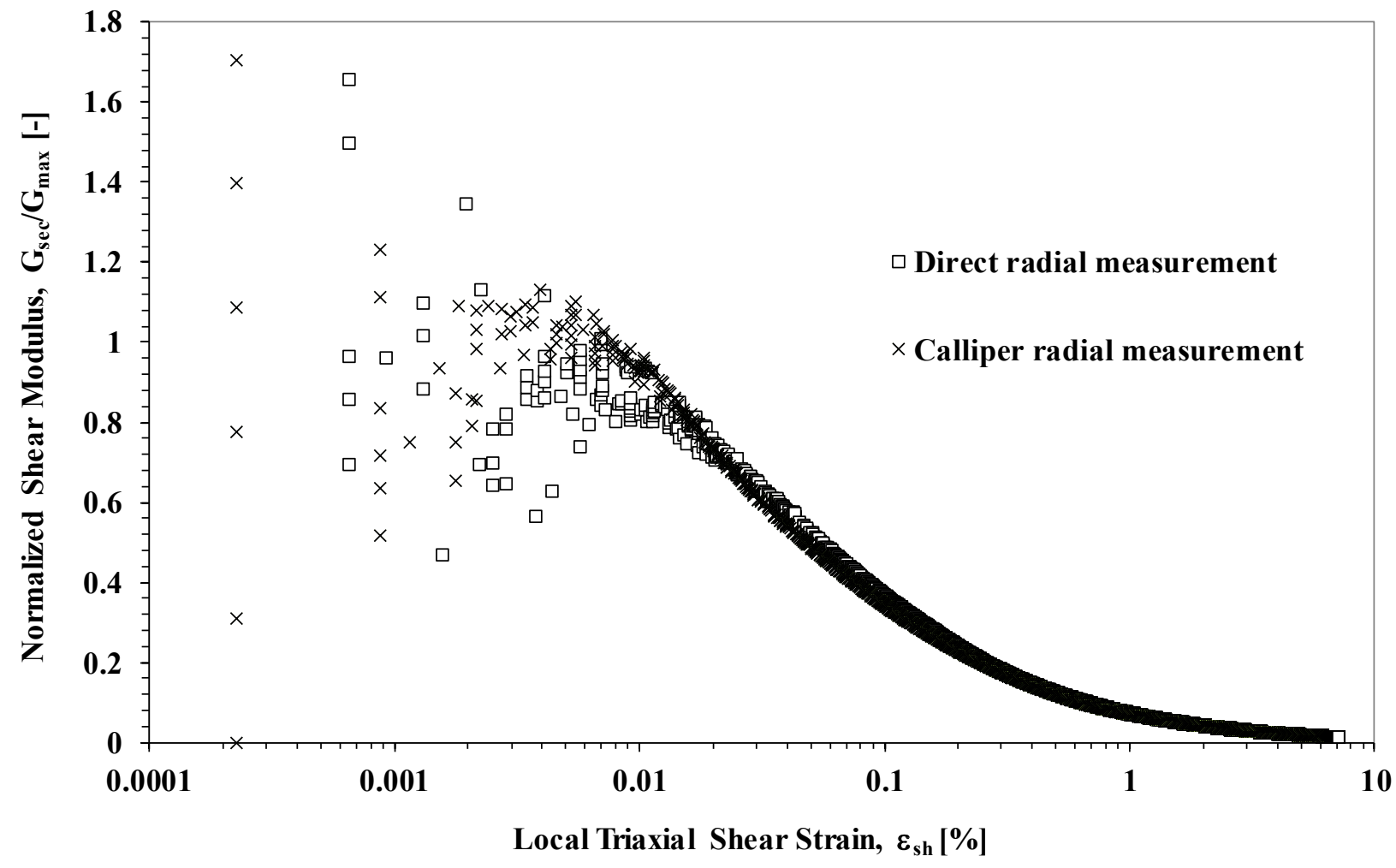

Fig. 4. Normalized shear modulus degradation curve

\footnotetext{
*Corresponding author: m.witowski@itb.pl
} 
The obtained values represent the degradation of the stiffness modulus of the tested specimen in the range of deformations from $0.00023 \%$ (in case of calliper type sensor) and $0.0007 \%$ (direct type sensor) to over $7 \%$ in both cases. The values of the shear modulus from the calliper type sensor, to the value of deformation of $0.007 \%$, indicate practically elastic response of the specimen to the load. In the case of the second sensor, no such dependence was observed due to larger dispersion of data. Moreover, the difference between the values of the secant modulus from both types of sensors becomes smaller when the deformation is greater than $0.02 \%$. Above this value, the results seem to be convergent.

\section{Conclusions}

A new systems for measuring axial and radial displacements has been developed and described. Based on results of the experiment presented herein, the following conclusions can be drawn regarding the obtained data:

1. On-sample strain sensors (axial and radial) based on encoders allow to determine stress-strain characteristics over a wide range of shear strains.

2. The sensor of radial deformation based on calliper mount allows for more accurate determination of this characteristic in relation to the radial sensor based on direct measurement.

3. The radial sensor, in the current configuration, is sensitive to the axiality of the specimen during shearing. Effects associated with specimen tilting may affect the distortion of radial deformation. To avoid this problem, the use of at least two sensors operating on opposite sides of the specimen is required, which is currently difficult to achieve due to hardware limitations

Based on these findings, the use of the presented sensors (axial and calliper radial) is promising for future practical applications. Based on the presented system, the author is currently conducting research on stiffness characteristics of soils which are subjected to significant axial deformations during the consolidation processes. The author is also working on increasing the resolution and accuracy of the presented system, as encoder-based displacement sensors with a higher resolution became commercially available and can be used to further improve measurement accuracy.

\section{References}

1. J. B. Burland, B.Simpson, and H. D. St. John, 7th Eur. Conf. Soil Mech. Found. Eng., no. September 1979, vol. 1, pp. 13-29, (1979).

2. J. B. Burland, Can. Geotech. J., vol. 26, no. 4, pp. 499-516, (1989).

3. J. H. Atkinson, Géotechnique, vol. 50, no. 5, pp. 487-508, (2000).

4. C. R. I. Clayton, Géotechnique, vol. 61, no. 1, pp. 5-37, (2011).

5. A. W. Bishop and D. J. Henkel, (1957).

6. R. J. Jardine, N. J. Symes, and J. B. Burland, Géotechnique, vol. 35, no. 3, pp. 378-382, (1985).

7. G. K. Scholey, J. D. Frost, D. C. F. Lo Presti, and M. Jamiolkowskt, Geotech. Test. J., vol. 18, no. 2, pp. 137-156, (1995).

8. X. Zhang, L. Li, G. Chen, and R. Lytton, Acta Geotech., vol. 10, no. 1, pp. 55-82, (2014).

9. Ł. D. Kaczmarek, P. J. Dobak, and K. Kiełbasiński, Stud. Geotech. Mech., vol. 39, no. 2, pp. 35-49, (2017).

10. M. Witowski, Geotech. Test. J., vol. 41, no. 6, p. 20170016, (2018).

11. G. Baldi, D. W. Hight, and G. E. Thomas, Advanced Triaxial Testing of Soil and Rock, ASTM STP 977. pp. 219-263, (1988).

12. Y. L. Kok, phd thesis, Cambridge, (2006).

13. S. K. Ackerley, J. R. Standing, and R. Hosseini Kamal, Géotechnique, vol. 66, no. 6, pp. 515522, (2016).

14. M. C. Santagata, J. T. Germaine, and C. C. Ladd, J. Geotech. Geoenvironmental Eng., vol. 131, no. $4,(2005)$.

15. R. Dyvik and C. Madshus, in Proceedings of the ASCE Annual Convention on Advances in the Art of Testing Soils under Cyclic Conditions, (1985).

16. J.-S. Lee and J. C. Santamarina, J. Geotech. Geoenvironmental Eng., vol. 131, no. 9, pp. 1063-1070, (2005).

17. M. Witowski and T. Godlewski, Sci. Rev. Eng. Environ. Sci., vol. 26, no. 3, pp. 307-316, (2017).

18. A. Gasparre, S. Nishimura, N. A. Minh, M. R. Coop, and R. J. Jardine, Géotechnique, vol. 57, no. 1, pp. 33-47, (2007).

19. A. Gasparre, D. W. Hight, M. R. Coop, and R. J. Jardine, Géotechnique, vol. 64, no. 12, pp. 942-953, (2014).

20. D. C. F. Lo Presti, M. Jamiolkowski, O. Pallara, A. Cavallaro, and S. Pedroni, Géotechnique, vol. 47, no. 3, pp. 603-617, (1997).

21. P. R. Smith, R. J. Jardine, and D. W. Hight, Géotechnique, vol. 42, no. 2, pp. 257-274, (1992).

\footnotetext{
* Corresponding author: m.witowski@itb.pl
} 